\title{
O Núcleo de Estudos em Filosofia e Saúde da Fundação Educacional Serra dos Órgãos: interfaces na formação médica
}

\author{
The Study Center in Philosophy and Health \\ of the Educational Foundation "Serra dos \\ Orgãos": interfaces in medical education
}

PALAVRAS-CHAVE

- Saúde;

- Medicina;

- Filosofia Médica;

- Educação Médica;

- Pesquisa.

KEY-WORDS

- Health;

- Medicine;

- Philosophy, Medical;

- Education, Medical;

- Research.

Recebido em: 24/01/2005

Reencaminhado em: 12/08/2005

Aprovado em: 14/10/2005

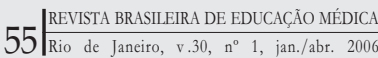

Rodrigo Siqueira-Batista ${ }^{1}$ Romulo Siqueira-Batista ${ }^{2}$

Andréia Patrícia Gomes ${ }^{3}$

Daniel Pinheiro Hernandez ${ }^{4}$

Sávio Silva Santos ${ }^{5}$

\begin{abstract}
RESUMO
Nos últimos anos, inúmeros problemas surgiram na área da saúde em decorrência, sobretudo, dos avanços ocorridos no campo das biotecnociências. Percebendo-se a exigüidade de espaço, no atual currículo médico, para a discussão de muitas dessas questões, alunos e professores da Fundação Educacional Serra dos Órgãos (FESO) propuseram a criação do Núcleo de Estudos em Filosofia e Saúde (NEFISA), espaço destinado a fomentar o debate, o ensino e a pesquisa sobre os assuntos que tenham sua emergência na interface da Filosofia com a Medicina e a Saúde. O escopo do presente artigo é apresentar o trabalho desenvolvido no NEFISA-FESO.
\end{abstract}

\begin{abstract}
Over the past few years many problems have arisen in the health area, mostly as a result of breakthroughs in biotechnosciences. Being aware of the lack of space in the present medical curriculum for discussing many of these issues, students and faculty members of the Educational Foundation "Serra dos Órgãos" (FESO) suggested the creation of a Study Center in Philosophy and Heaslh (NEFISA), a space intended for fostering discussion, teaching and research on subjects that are interfacing philosophy, medicine and health. The purpose of this article is to present the work done at NEFISA-FESO.
\end{abstract}

\footnotetext{
${ }^{1}$ Médico e Filósofo. Doutor em Ciências, Professor Titular de Clínica Médica do Curso de Medicina, da Disciplina de Filosofia do Curso de Ciência da Computação, Centro de Ciências Humanas e Sociais. Coordenador do Núcleo de Estudos em Filosofia e Saúde, Fundação Educacional Serra dos Órgãos, Teresópolis, Rio de Janeiro, Brasil.

${ }^{2}$ Filósofo. Doutorando em Filosofia, Professor Assistente da Disciplina de Filosofia do Curso de Ciência da Computação, Coordenador do Núcleo de Estudos em Filosofia e Saúde, Professor Assistente da Disciplina de Saúde Coletiva, Curso de Medicina, Fundação Educacional Serra dos Órgãos, Teresópolis, Rio de Janeiro, Brasil.

${ }^{3}$ Médica. Mestre em Medicina Tropical, Professora Titular das Disciplinas de Clínica Médica e Doenças Infecciosas e Parasitárias, Curso de Medicina. Professora Associada do Núcleo de Estudos em Filosofia e Saúde, Fundação Educacional Serra dos Órgãos. Médica Infectologista da Assessoria de DST/AIDS, Centro de Vigilância Epidemiológica, Secretaria de Estado de Saúde - RJ, Rio de Janeiro, Brasil.

${ }^{4}$ Médico. Mestre em Educação, Professor Titular da Disciplina de Histologia, Cursos de Medicina, Enfermagem e Odontologia, Professor Titular da Disciplina de Metodologia da Pesquisa, Cursos de Ciências da Computação, Administração e Ciências Contábeis. Professor Associado do Núcleo de Estudos em Filosofia e Saúde, Fundação Educacional Serra dos Órgãos. Chefe da Divisão de Vigilância Epidemiológica, Secretaria de Saúde de Teresópolis - RJ, Teresópolis, Rio de Janeiro, Brasil.

${ }^{5}$ Médico. Mestre em Educação, Professor Titular da Disciplina de Clínica Médica, Curso de Medicina, Tutor do Internato de Clínica Médica, Curso de Medicina, Professor Associado do Núcleo de Estudos em Filosofia e Saúde, Fundação Educacional Serra dos Órgãos, Teresópolis, Rio de Janeiro, Brasil.
} 


\section{INTRODUÇÃO}

A medicina é uma das mais antigas atividades humanas cuja origem está mesclada aos primórdios do próprio Homo sapiens sapiens. Ao longo de sua história, e em composição com as transformações culturais dos povos, esta $\tau \varepsilon \dot{\chi} \chi \vee \eta$ - ou seja, arte, no mais lídimo sentido grego —coloca- se como um campo para ação do homem, possibilitando, assim, a geração de inúmeras questões sobre os movimentos da existência. ${ }^{1}$

A partir da segunda metade do século $X X$, surgiram diferentes problemas relacionados ao saber-fazer médico, os quais estão, em grande medida, atrelados à "explosão" tecnológica vivida pelas sociedades ocidentais: os limites para o conhecimento e condução da vida, a deterioração da prática médica, a intensificação da relação médico-máquina - geralmente em detrimento da relação médico-paciente - os limiares do viver e do morrer - medicalizados e "varridos" para o interior frio e asséptico dos nosocômios somente para se citar alguns, caracterizando um genuíno ocaso das certezas, manifesto nas mais diferentes ordens de discurso. ${ }^{2,3}$

Se o conjunto das conexões entre a Filosofia e a Medicina é pautado pela atuação do médico, torna-se fácil compreender que aquela abre perspectivas para o estabelecimento de diferentes interrogações no âmbito desta última, especialmente no que diz respeito aos aspectos éticos e epistemológicos. Tais campos de investigação podem, então, trazer inegáveis contribuições para um melhor delineamento do que é a Medicina e, sobretudo, dos limites de sua legitimidade e de sua intervenção na vida do homem, possibilitando a adoção de uma postura mais crítica sobre sua prática. Ademais, expandindo-se os horizontes da discussão do contexto da Medicina para a Saúde - compreendida em seu sentido mais lato, e não apenas como bem-estar físico, psíquico e social -, as contribuições da Filosofia podem tornar-se ainda mais promissoras, ${ }^{4,5}$ permitindo o estabelecimento de um foro para colocação dos problemas e formulação de conceitos, instrumentalizando, assim, os profissionais para uma prática mais equânime.

Com base nesse panorama, a Fundação Educacional Serra dos Órgãos (FESO) acolheu, em toda sua plenitude, a proposta apresentada por alunos e professores da instituição para a criação de um núcleo de pesquisas que contemplasse as ricas possibilidades existentes na interseção Filosofia e Saúde. Tal foi a decisão institucional que permitiu a criação do Núcleo de Estudos em Filosofia e Saúde (NEFISA), em 2002. Apresentar os caminhos percorridos pelo NEFISA nestes pouco mais de dois anos, desde a sua criação, é o escopo do presente manuscrito.

\section{A FUNDAÇÃO EDUCACIONAL SERRA DOS ÓRGÃOS}

A criação da FESO - uma fundação de direito privado sem fins lucrativos - ocorreu em 1966, pelo Decreto Municipal número 02/66 de 20 de janeiro de 1966, e foi fruto de importante mobilização e participação social, tendo como objetivo principal a atenção ao Ensino Médio, Profissional e Superior. ${ }^{6}$ O surgimento da Faculdade de Medicina de Teresópolis, pioneiro curso de graduação da FESO, ocorreu em 1969, a com autorização dada pelo Decreto Federal número 66.436 de 10 de abril de 1970 . O reconhecimento foi concedido pelo Decreto número 75.237 de 16 de janeiro de 1975.6 Em seguida, foram implantados os demais cursos da instituição, de modo que, atualmente, a FESO é constituída por dez cursos de graduação, dos quais cinco compõem o Centro de Ciências Biomédicas (CCBM) - Enfermagem, Fisioterapia, Medicina, Medicina Veterinária e Odontologia - e os outros cinco, o Centro de Ciências Humanas e Sociais (CCHS) Administração, Ciências Contábeis, Ciência da Computação, Direito e Pedagogia. As instalações da FESO ocupam 26.044,32 $\mathrm{m}^{2}$ de área construída (em 838.262,00 m² de terrenos), distribuídas em cinco locais - Campus Sede, Campus Quinta do Paraíso, Unidade FESO Proarte, Unidade Básica de Saúde da Beira Linha e Hospital das Clínicas de Teresópolis Costantino Ottaviano. ${ }^{6}$

\section{O NÚCLEO DE ESTUDOS EM FILOSOFIA E SAÚDE (NEFISA)}

A fundação do NEFISA-FESO ocorreu em agosto de 2002, após um período de seis meses marcados por intensas discussões acerca da abrangência e da natureza do núcleo. O "deflagrador" do processo foi o curso Introdução ao Pensamento Científico, realizado no período de janeiro - fevereiro de 2002. Em decorrência da enorme quantidade de questionamentos e idéias, formulados durante o evento, tornou-se bastante clara, para os docentes e discentes envolvidos, a necessidade de se constituir um foro permanente para a discussão.

Após sua implantação, o NEFISA-FESO passou a funcionar com base no trabalho de cinco docentes, responsáveis pelas atividades de ensino e pesquisa do núcleo, os quais assinam este trabalho.

Os discentes, cuja participação foi fundamental no processo de instalação e condução do NEFISA-FESO, têm sua agregação ao grupo instituída sob a forma de estágio oficial, com duração, prorrogável, de um ano. Até este momento já passaram pelo NEFISA-FESO vinte estagiários provindos dos cursos de Medicina, Pedagogia e Direito.

Os participantes se encontram semanalmente para planejamento dos eventos, discussão dos projetos de pesquisa e distribuição das atividades de organização da biblioteca do núcleo. Atualmente, o trabalho realizado pelo corpo acadêmico do NEFISA-FESO está estruturado em atividades de ensino e pesquisa, tal qual o explicitado a seguir. 


\section{Ensino}

As atividades de ensino são abertas à comunidade acadêmica da FESO - bem como à população extra-instituição -, contando com a participação de docentes do NEFISA-FESO e de convidados. Subdividem-se em quatro categorias:

(1) Cursos de Extensão com enfoque em problemas filosóficos na área da saúde. Já foram oferecidos:

- Formação em Filosofia e Saúde;

- Bioética: Problemas da Medicina no Século XXI;

- Fundamentos do Método Clínico;

- Introdução à Filosofia de Platão;

- Leituras em Ética e Bioética;

- I Curso Imagens \& Conceitos - O Cinema e a Filosofia;

- II Curso Imagens \& Conceitos - O Cinema e a Filosofia;

- III Curso Imagens \& Conceitos - O Cinema e a Filosofia;

- Introdução ao Pensamento de Schopenhauer.

(2) Seminários Filosofia, Saúde e Cultura (SFSC), idealizados originalmente para contribuir com a formação profissional em Saúde - na verdade tem havido participação massiva de pessoas externas ao NEFISA-FESO e à própria FESO, caracterizando, assim, um democrático espaço para "circulação" das idéias - , discutindo-se os aspectos mais importantes da saúde, sobretudo em suas interfaces com a filosofia e a cultura, possibilitando uma abordagem mais abrangente do binômio saúde-doença capaz de gerar profissionais com maior grau de interesse não só nas questões biológicas, mas também nos aspectos sociais e psíquicos de seus pacientes. Foram, até o momento, apresentados os seguintes SFSC:

- Pós-Modernidade e Biopoder;

- Física Contemporânea, Saúde e Sociedade;

- Heidegger e a Questão do Homem;

- As Origens da Universidade Brasileira;

- Bioética: Notação Histórica e Problemas Atuais;

- Alcoolismo e a Experiência da Finitude;

- Platão e a Poesia;

- As Origens da Bioética;

- O Eterno Retorno e o Pensamento Trágico em Nietzsche;

- Melancolia, Filosofia e Literatura;

- Racionalidade e Estética na Música Ocidental: da Naturalização dos Elementos Musicais e da Subversão dos Compositores Eruditos;

- Por una Razón Metafórica.

(3) Colóquios, cujo objetivo é apresentar à comunidade acadêmica as atualidades e caminhos na pesquisa envolvendo Humanidades e Saúde. Já foram realizados:

- I Colóquio de História da Medicina;

- I Colóquio Serrano Sobre a Morte e o Morrer.
(4) Participação regular em atividades realizadas pelos cursos de graduação da instituição, como painéis e conferências versando sobre Bioética e História da Medicina nas disciplinas de Clínica Cirúrgica, Clínica Médica, Propedêutica Médica, Radiologia / Diagnóstico por Imagem e Saúde Coletiva, do curso de Medicina, e de Antropologia e Sociologia, do curso de Fisioterapia.

\section{Pesquisa}

Vêm sendo desenvolvidas atividades que enfocam a discussão dos temas filosóficos de importância na Saúde. Encontram-se em andamento projetos de pesquisa nas seguintes linhas:

(1) Filosofia e Medicina na Antigüidade;

(2) A morte e o processo de morrer;

(3) Epistemologia, ciência e saúde;

(4) História da Medicina;

(5) Saúde e sociedade; e

(6) Ética e bioética;

Dentro da perspectiva de uma estreita colaboração entre docentes e discentes, já podem ser apontados alguns resultados bastante favoráveis no âmbito das atividades de pesquisa: vinte e oito comunicações apresentadas em congressos - locais (9), nacionais (11) e internacionais (8) - e dezesseis artigos publicados em diferentes periódicos (ver referências números 7 a 22), 7-22 boa parte dos quais resultantes do intercâmbio do núcleo com docentes e pesquisadores de outras instituições de pesquisa. Uma síntese histórica dos trabalhos produzidos pelo NEFISA-FESO é apresentada nos gráficos, a seguir.

\section{GRÁFICO 1}

Número de comunicações apresentadas em congressos de 2002 a 2004

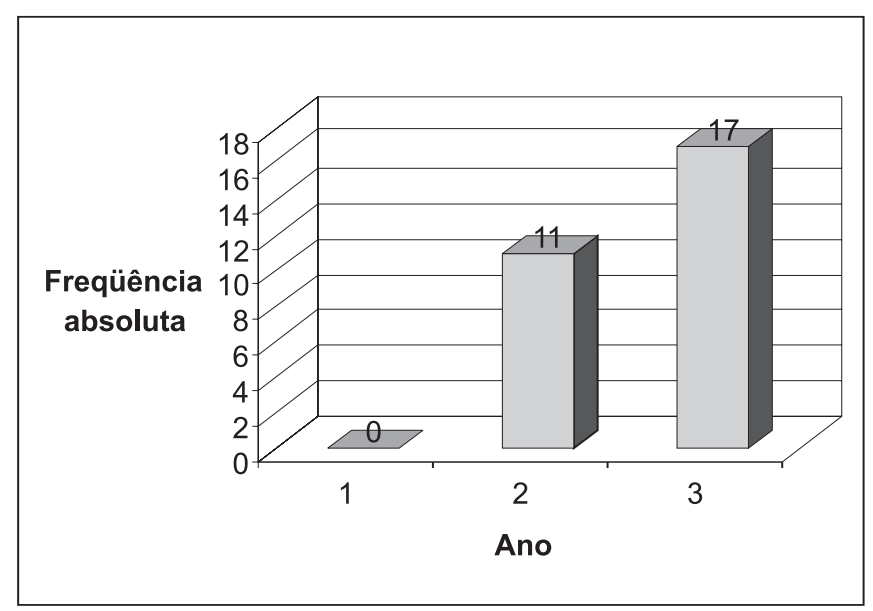




\section{GRÁFICO 1}

Número de artigos publicados

em revistas de 2002 a 2004

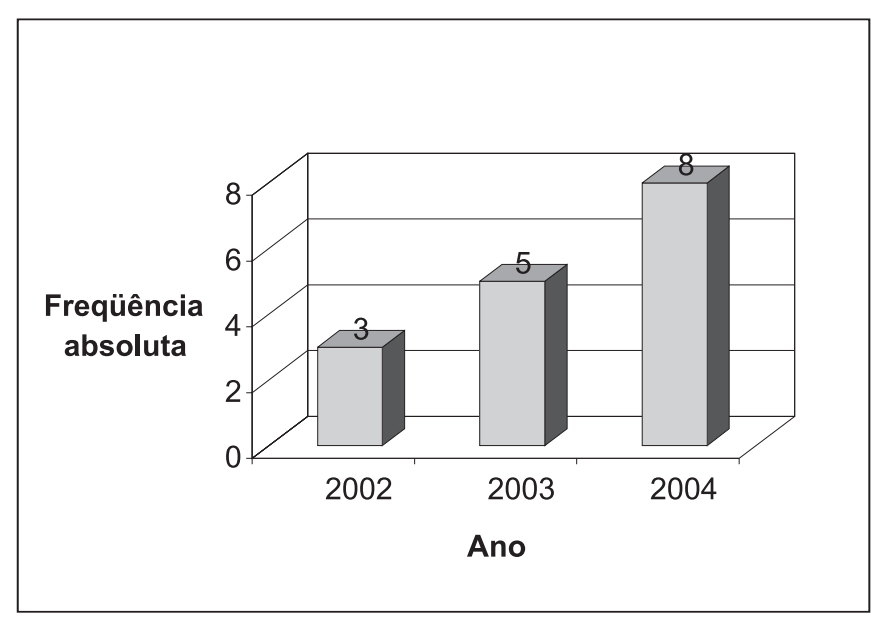

Em acréscimo à produção acima descrita, deve-se mencionar a apresentação, pelos estagiários do NEFISA-FESO, de onze comunicações no I Seminário de Pesquisa do Núcleo de Estudos em Filosofia e Saúde - FESO, no ano de 2003, as quais foram fruto das pesquisas desenvolvidas pelos discentes do Núcleo.

\section{CONSIDERAÇÕES FINAIS}

O trabalho desenvolvido no NEFISA-FESO tem sido capaz de demonstrar a existência de íntimas e estreitas relações entre a Filosofia e a Medicina, no campo ampliado das discussões sobre a saúde, a sociedade e a cultura. ${ }^{23,24}$ As atividades realizadas, desde a criação do núcleo, têm facultado aos docentes e discentes envolvidos um fecundo espaço para reflexão sobre a prática médica - suas doutrinas e métodos, o alcance de sua técnica e os seus liames morais - permitindo a compreensão da Medicina como ciência humana. Ademais, as discussões e investigações realizadas têm possibilitado aos participantes e à comunidade acadêmica da FESO uma formação cultural ampliada.

A despeito dos resultados iniciais mostrarem-se favoráveis, permanece como desafio a elaboração de mecanismos e/ou instrumentos para mensuração do impacto da criação do NEFISA-FESO na formação acadêmica dos médicos e dos demais profissionais de saúde para a sociedade brasileira.

\section{AGRADECIMENTOS}

Os autores são gratos aos estudantes Ana Karla Albuquerque, Fábio Gonzales, Fernando Siqueira Pontes, Gilberto Maia, Guilherme Almeida, Juan Cedrola, Manuela Müller,
Maurício Erwin, Péricles Salmazo, Renata Lisboa, Thiago Furquim, Tiago Bezerra, William Santussi, Diana Watts Silva Santos, sem os quais o NEFISA não teria mantido sua razão de ser.

\section{REFERÊNCIAS}

1. Siqueira-Batista R. Deuses e Homens. Mito, Filosofia e Medicina na Grécia Antiga. São Paulo: Landy; 2003.

2. Schramm FR. A moralidade da prática de pesquisa nas ciências sociais: aspectos epistemológicos e bioéticos. Ciên Saúde Coletiva. 2004; 9(3):773-784.

3. Siqueira-Batista R. Bioética e compaixão. J Cremerj. 2004; v. XVII:15.

4. Martins A. Filosofia e saúde: métodos genealógico e filosófico-conceitual. Cad Saúde Pública. 2004; 20(4):950-958.

5. Ayres JR. Norma e formação: horizontes filosóficos para as práticas de avaliação no contexto da promoção da saúde. Ciên Saúde Coletiva. 2004; 9(3):583-592.

6. Tostes LEP. A Fundação Educacional Serra dos Órgãos e a formação social de Teresópolis. Teresópolis (RJ): Papel \& Virtual; 2003. (Coleção FESO).

7. Gomes AP. Breve resenha histórica da Síndrome de Imunodeficiência Adquirida (AIDS). Rev FMT. 2004; 6(1): 10-12.

8. Costa CRBSF, Siquiera-Batista R. As teorias do desenvolvimento moral e o ensino médico: uma reflexão pedagógica centrada na autonomia do educando. Rev Bras Edu Méd. 2004; 28(3):242-250.

9. Siqueira-Batista R. O nascimento da clínica: a doutrina e o método na medicina hipocrática. Rev FMT. 2004; 6(1): 1618.

10. Siqueira-Batista R. Eutanásia e compaixão. Rev Bras Cancerol. 2004; 50(4):334-340.

11. Siqueira-Batista R, Gomes AP, Siqueira-Batista R, Santos SS, Frias IM. Anamnese: a base do diagnóstico em Medicina. Rev FMT. 2004; 6(1):19-22.

12. Siqueira-Batista R, Schramm FR. A filosofia de Platão e o debate bioético sobre o fim da vida: interseções no campo da Saúde Pública. Cad Saúde Pública. 2004; 20(2):855-865.

13. Siqueira-Batista R, Schramm FR. Eutanásia: pelas veredas da morte e da autonomia. Ciên Saúde Coletiva. 2004; 9(1):31-41.

14. Siqueira-Batista R, Schramm FR. Platão e a Medicina. História, Ciências, Saúde - Manguinhos. 2004; 11(3):619-634.

15. Bezerra TS, Almeida GC, Cedrola JPV. “Eutanásia: sim ou não?" - É possível responder? Rev FMT. 2003; 5(2): 45-46. 
16. Siqueira-Batista R. Lucrécio e a natureza das coisas: dispersão infinita do Todo. Rev Estudos Transdisciplinares 2003; 2(2): 71-82.

17. Siqueira-Batista R. O Espírito helênico: o poeta, o filósofo e o médico na Grécia antiga. Rev Bras Fil. 2003; 212: 465-482.

18. Siqueira-Batista R, Siqueira-Batista R, Helayël-Neto JA. A realidade quântica - notas históricas e apontamentos epistemológicos. Physicae. 2003; 4(4):33-38.

19. Siqueira-Batista R, Siqueira-Batista R, Braga EA, HelayëlNeto JA. O atomismo de Lucrécio: física e descontinuidade. Physicae. 2003; 4(4):19-22.

20. Siqueira-Batista R. Inspiração versus empirismo: Filosofia e Medicina na Grécia antiga. Análogos. 2002; 1(1):184-201.

21. Siqueira-Batista R, Siqueira-Batista R. De como filosofar é aprender a morrer: o pensamento de Michel de Montaigne como pressuposto na discussão sobre a morte e o processo de morrer na prática médica. Cad Saúde Coletiva 2002; 10(1):9-18.

22. Siqueira-Batista R, Siqueira-Batista R. História da Medicina: a filosofia pré-socrática e suas relações com a Medicina grega antiga. Rev FMT. 2002; 6(1): 23-28.
23. Ribeiro JM. Técnica médica e singularidades. In: Vaitsman J, Girardi S. A ciência e seus impasses: debates e tendências em filosofia, ciências sociais e saúde. Rio de Janeiro: Editora Fiocruz; 1999.

24. Schramm FR. Niilismo tecnocientífico, holismo moral e a 'bioética' global de V. R. Potter. História, Ciências, Saúde Manguinhos. 1997; 4(1): 95-115.

Trabalho realizado no Núcleo de Estudos em Filosofia e Saúde (NEFISA), Fundação Educacional Serra dos Órgãos (FESO).

\section{Endereço para correspondência}

Prof. Rodrigo Siqueira Batista

Fundação Educacional Serra dos Órgãos (FESO)

Centro de Ciências Biomédicas (CCBM)

Núcleo de Estudos em Filosofia e Saúde (NEFISA)

Av. Alberto Torres, 111 - Alto.

CEP: 25964-000 - Teresópolis - RJ

e-mail: anaximandro@hotmail.com 